\title{
Characterization of EGFR family gene aberrations in cholangiocarcinoma
}

\author{
XIAOQING YANG ${ }^{1}$, WEISHAN WANG $^{2}$, CHUNNI WANG $^{1}$, LIN WANG $^{1,3}$, MUYI YANG $^{1}$, MEI QI $^{1}$, \\ HONG SU ${ }^{1}$, XIUBIN SUN ${ }^{4}$, ZHIYAN LIU ${ }^{1}$, JUAN ZHANG ${ }^{5}$, XIAOMIN QIN ${ }^{5}$ and BO HAN ${ }^{1,5}$ \\ ${ }^{1}$ Department of Pathology, Shandong University Medical School, Jinan, Shandong; ${ }^{2}$ Department of General Surgery, \\ Yishui Central Hospital, Linyi, Shandong; ${ }^{3}$ Research Center for Medicinal Biotechnology, Shandong Academy of \\ Medicinal Sciences, Jinan, Shandong; ${ }^{4}$ Department of Statistics, Shandong University School of Public Health, \\ Jinan, Shandong; ${ }^{5}$ Department of Pathology, Shandong University Qilu Hospital, Jinan, Shandong, P.R. China
}

Received February 7, 2014; Accepted April 7, 2014

DOI: $10.3892 /$ or.2014.3261

\begin{abstract}
Cholangiocarcinoma (CCA) is a highly lethal malignancy of the biliary tract with very few treatment options. Epidermal growth factor receptor (EGFR) and human epidermal growth factor receptor (HER2) have been considered as potential therapeutic targets in CCA. In the present study, we attempted to clarify the clinicopathological significance of all EGFR family members, EGFR, HER2, HER3 and HER4, across the full spectrum of CCAs. Immunohistochemistry and FISH were performed to validate expressions and genetic aberrations of these molecules retrospectively in $175 \mathrm{CCA}$ patients. EGFR, HER3 and HER4 were overexpressed in $20(30.8 \%), 8(12.3 \%)$ and $41(63.1 \%)$ of the 65 intrahepatic cholangiocarcinomas (IHCCs), and in 23 (20.9\%), 13 (11.8\%) and $62(56.4 \%)$ of the 110 extrahepatic cholangiocarcinomas (EHCCs), respectively. Overexpression of HER2 was exclusively identified in EHCCs, among which the rate was $4.5 \%$ (5/110). A significant association was identified between EGFR amplification and EGFR overexpression $(\mathrm{P}=0.002)$. Similarly, HER2 amplification was strongly associated with HER2 overexpression $(\mathrm{P}<0.001)$. Multivariate analysis suggested that EGFR overexpression is an independent prognostic factor in IHCC, but not in EHCC cases [HR (95\% CI): 3.689 (1.25310.587), $\mathrm{P}=0.018]$. Notably, for the first time, we demonstrated HER4 expression is a prognostic factor in EGFR-negative IHCC patients. In vitro data further suggested a tumorsuppressor role of HER4 in CCA. siRNA knockdown of HER4 significantly increased RBE cell migration and invasion. By contrast, HER4 overexpression decreased proliferation of HuCCT-1 cells and their migratory and invasive capacity. In summary, our results revealed expression of the EGFR family
\end{abstract}

Correspondence to: $\operatorname{Dr}$ Bo Han, Department of Pathology, Shandong University Medical School, 44 Wenhua Xi Road, Jinan, Shandong 250012, P.R. China

E-mail: boh@sdu.edu.cn

Key words: cholangiocarcinoma, EGFR, HER2, HER4, prognosis members in CCA development and progression. CCAs differentially express HER2 protein based on tumor location. HER4 expression status allows stratification of CCA patients into different survival categories.

\section{Introduction}

Cholangiocarcinoma (CCA) is a rare but highly aggressive cancer, accounting for $3 \%$ of all gastrointestinal malignancies (1). CCA is characterized by poor responsiveness to chemotherapy and radiotherapy in the majority of cases $(2,3)$. Surgical resection is the only potentially curative option. Therefore, novel biomarkers are urgently needed for CCA management and treatment.

The human epidermal growth factor receptor (EGFR) family consists of four members: HER1 (EGFR), HER2 (c-erbB-2), HER3 (c-erbB-3) and HER4 (c-erbB-4) (4). These receptors activate multiple downstream pathways in response to extracellular ligands, regulating diverse processes that include differentiation, migration, proliferation and survival $(5,6)$. Aberrations in EGFR family members play a role in the development and progression of many human cancers (7-9). Extensive studies have reported either the overexpression or amplification of EGFR and HER2 in different malignancies $(10,11)$. Accordingly, current evidence suggests that HER3 expression is associated with increased cellular proliferation whereas HER4 activation seems to mainly mediate antiproliferative effects (12-14).

In CCA, overexpression of EGFR and HER2 are thought to be prognostic factors and targets of novel biologic agents (15). Of note, a series of studies have revealed overexpression of EGFR and HER2, amplification and mutations of these genes (15-17). Although the clinical significance of such overexpression is not fully clear, some case reports and phase II trials have reported promising results targeting EGFR in CCA (18). By contrast, the data of HER3 and HER4 is very limited. Most recently, Lee et al (19) reported that HER3 is overexpressed in a subset of extrahepatic cholangiocarcinoma (EHCC) patients and HER3 overexpression is correlated with decreased patient survival. The biological function and prognostic role of HER4 has thus far not been investigated in CCA. 
According to the 7th edition of the Union for International Cancer Control-American Joint Committee on Cancer (UICC/ AJCC), CCAs are classified as intrahepatic cholangiocarcinomas (IHCCs) and EHCCs, the latter being further divided into perihilar CCAs and distal CCAs. Although linked anatomically and histopathologically, it is unclear whether CCA patients from different sites share common pathogenetic features. It has been reported that CCA differentially expresses cell cycle-regulatory proteins based on tumor location and morphology (20).

In the present study, we comprehensively characterized and compared differential gene expression of all EGFR family members across the full spectrum of CCAs. We aimed to define differential expression of EGFR family members based on anatomic site of origin to establish new potential prognostic factors in CCA.

\section{Patients and methods}

Patients and tissue microarray (TMA) construction. The present study consisted of 175 CCAs (male, 106; female, 69) who underwent surgical resections between 2004 to 2011 at the Qilu Hospital of Shandong University (Jinan, China). Follow-up time ranges from 3 to 98 months (mean, 26 months). A total of two TMAs were constructed. Two cores $(1.0 \mathrm{~mm}$ in diameter) were taken from each representative tumor focus and the morphology was evaluated by two pathologists (B.H. and X.Y.). Detailed clinical and pathological profiles were obtained from medical records and maintained in a secure relational database with TMA data. Tumor staging and histological classification were assessed according to AJCC 7th Edition of TNM Staging (21). Patient demographics are shown in Table I. Informed written consent was obtained from the CCA patients. The study and the consent procedures were approved by the Institutional Review Board at the School of Medicine of Shandong University. All cases were anatomically classified into two groups: IHCC and EHCC. Hilar and distal CCA were classified as EHCC. The numbers of IHCC and EHCC cases were 65 and 110, respectively.

Immunohistochemistry (IHC). IHC was performed as previously described (22). Briefly, the slides were deparaffinized by successive passages through xylene and ethanol. Antigen retrieval was performed by microwave pretreatment in $0.01 \mathrm{M}$ citrate buffer ( $\mathrm{pH} \mathrm{6.0)}$ for $15 \mathrm{~min}$. The primary antibodies used were anti-EGFR (1:500; Dako), anti-HER2 (1:500; Dako) anti-HER3 (sc-415, 1:500; Santa Cruz Biotechnology, Santa Cruz, CA, USA) and anti-HER4 (sc-283, 1:500; Santa Cruz Biotechnology). The slides were incubated overnight at $4^{\circ} \mathrm{C}$. For visualization, 3,3-diaminobenzidine tetrahydrochloride was used as chromogen. The slides were evaluated by two independent pathologists (B.H. and X.Y.) who were blinded to the clinical data. For EGFR and HER2, only the membrane immunostaining was scored following a four-step scale (scores $0,1+, 2+$ and $3+$ ). For HER2, we followed the consensus panel recommendations on HER2 scoring for breast cancer (8). Slides with a score of $2+$ or $3+$ were classified as positive or expressed, in contrast to slices with a score of 0 or $1+$, which were defined as negative. For HER3 and HER4, nuclear and cytoplasmic staining was evaluated using the Rajkumar score (23), which was built by multiplying the scores of 2 param-
Table I. Summary of CCA patient demographics.

\begin{tabular}{|c|c|c|}
\hline Parameters & $\operatorname{IHCC}(\%)$ & $\operatorname{EHCC}(\%)$ \\
\hline \multicolumn{3}{|l|}{ Age (years) } \\
\hline$<60$ & $35(53.8)$ & $73(66.4)$ \\
\hline$\geq 60$ & $30(46.2)$ & 37 (33.6) \\
\hline \multicolumn{3}{|l|}{ Gender } \\
\hline Male & $29(44.6)$ & $77(70.0)$ \\
\hline Female & $36(55.4)$ & $33(30.0)$ \\
\hline \multicolumn{3}{|c|}{ Tumor size $(\mathrm{cm})^{\mathrm{a}}$} \\
\hline$<5$ & $22(33.8)$ & $68(61.8)$ \\
\hline$\geq 5$ & $43(66.2)$ & $42(38.2)$ \\
\hline \multicolumn{3}{|c|}{$\begin{array}{l}\text { Histological } \\
\text { differentiation }\end{array}$} \\
\hline Well & $17(26.2)$ & $56(50.9)$ \\
\hline Moderate & $31(47.7)$ & 37 (33.6) \\
\hline Poor & $17(26.2)$ & $17(15.5)$ \\
\hline \multicolumn{3}{|c|}{ Perineural invasion } \\
\hline Negative & $57(87.7)$ & $80(72.7)$ \\
\hline Positive & $8(12.3)$ & $30(27.3)$ \\
\hline \multicolumn{3}{|c|}{ Microvascular invasion } \\
\hline Negative & $51(78.5)$ & $97(88.2)$ \\
\hline Positive & $14(21.5)$ & $13(11.8)$ \\
\hline \multicolumn{3}{|c|}{ Venous invasion } \\
\hline Negative & $62(95.4)$ & $103(93.6)$ \\
\hline Positive & $3(4.6)$ & $7(6.4)$ \\
\hline \multicolumn{3}{|l|}{ T stage } \\
\hline $\mathrm{I}+\mathrm{II}$ & $51(78.5)$ & $57(51.8)$ \\
\hline III + IV & $14(21.5)$ & $53(78.2)$ \\
\hline \multicolumn{3}{|l|}{$\mathrm{N}$ stage } \\
\hline Negative & $50(76.9)$ & $78(70.9)$ \\
\hline Positive & $15(23.1)$ & $32(29.1)$ \\
\hline \multicolumn{3}{|l|}{ UICC stage } \\
\hline $\mathrm{I}+\mathrm{II}$ & $40(61.5)$ & $63(57.3)$ \\
\hline III + IV & $25(38.5)$ & $47(42.7)$ \\
\hline
\end{tabular}

${ }^{\mathrm{a}}$ In EHCC tumor size was categorized by $<3$ and $\geq 3$, respectively.

eters, the staining intensity (range, 0-3) and the percentage of positive cells (range, $0-4 ; 0,0-10 \% ; 1,11-25 \% ; 2,26-50 \%$; $3,51-75 \%$; and $4,76-100 \%)$. Slides with scores of $\geq 8$ were classified as overexpression and slides with scores $<8$ as nonoverexpression.

Fluorescence in situ hybridization (FISH). FISH analysis for EGFR and HER2 gene aberrations was performed as previously described (10). Briefly, the GLP EGFR/CSP 7 probe and GLP HER2/CSP17 (Beijing GP Medical Technologies, Beijing, China) were utilized and slides were examined using an ImagingZ1 microscope (Carl Zeiss, Oberkochen, Germany). FISH signals were scored manually (100x oil immersion) in morphologically intact and non-overlapping nuclei by a pathologist (B.H.) and a minimum of 50 cancer cells from each site were recorded. Cancer sites with very weak or no signals were recorded as insufficiently hybridized. 

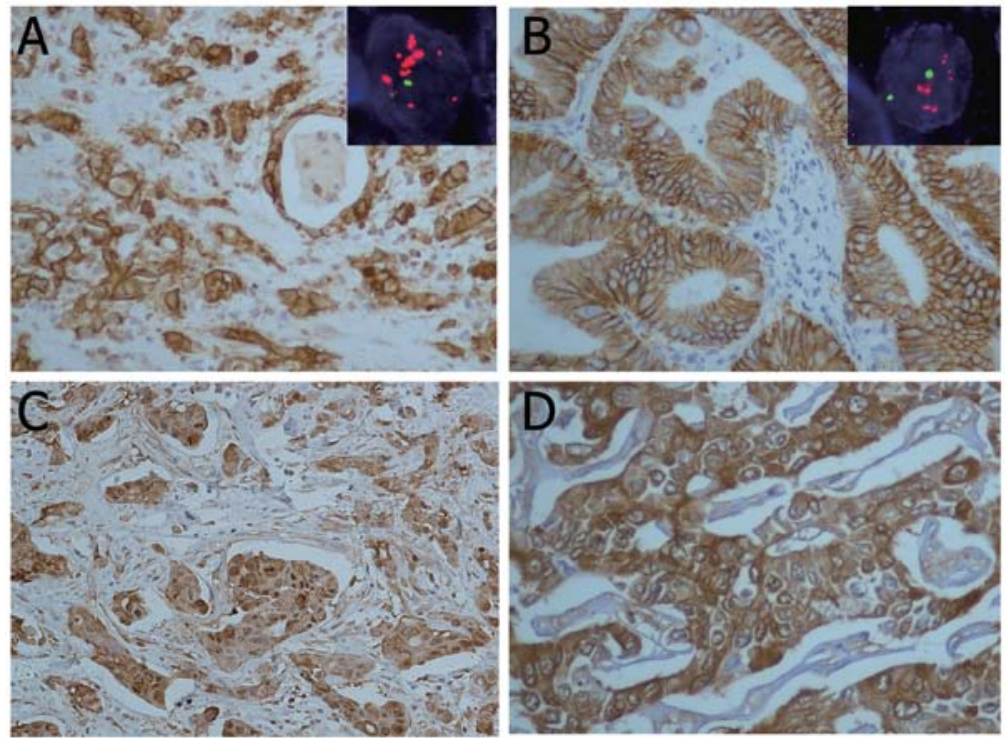

Figure 1. Representative positive cases of CCA for EGFR family members by IHC and FISH. (A and B) Strong membrane staining (score 3) of EGFR and HER2, respectively. Insert areas with representative FISH image of amplification of EGFR and HER2, respectively. (C) Strong expression of HER3 in cytoplasm and nuclei of tumor cells. (D) Strong expression of HER4 predominantly in cytoplasm of CCA cells.

A previously documented method was utilized to validate genetic aberrations of EGFR and HER2 (22). A case was scored as amplification when $>10 \%$ of tumor cells displayed either definite cluster of locus probe signals or EGFR (HER2):CEP 17 ratio $>2$.

Cell culture and reagents. The CCA cell lines RBE, HuCCT-1, QBC939 and one breast cancer cell line MCF-7 were obtained from the Cell Bank of the Chinese Academy of Sciences (Shanghai, China) and cultured following the manufacturer's instructions.

Western blot analysis. Western blot analysis was performed as previously described (22). Briefly, the membrane was incubated overnight at $4^{\circ} \mathrm{C}$ with primary antibody for anti-HER 4 (sc-283, 1:1,000; Santa Cruz Biotechnology). The secondary antibody was a goat anti-rabbit antibody at a dilution of 1:5,000 and the signals were detected with RapidStep ${ }^{\mathrm{TM}}$ ECL reagent (Millipore Corp., Billerica, MA, USA). Three independent experiments were performed. For analysis of the western blot images, the ImageJ software (1.37v; Wayne Rasband, NIH, Bethesda, MD, USA) was used.

In vitro overexpression of HER4. Human HER4 cDNA was subcloned into the pcDNA3.1 eukaryotic expression vectors. HER4 and empty control plasmids were independently transfected into HuCCT-1 cells using Lipofectamine (Invitrogen, Carlsbad, CA, USA) according to the manufacturer's protocol.

siRNA knockdown. siRNA transfection on CCA cell line RBE was carried out using Lipofectamine 2000 (Invitrogen) according to the manufacturer's protocol. Three specific siRNAs for each gene were designed and synthesized by GenePharma (Shanghai, China), respectively. The most effective single siRNA-HER4 (sense strand, 5'-GCGCAGGAAA CAUCUAUAUTT-3' and antisense strand, 5'-AUAUAGAUG GUUUCCUGCGCTT-3') was used for further experiments.
Non-specific negative control siRNAs were also used (sense strand, 5'-UUCUCCCAACGUGUCACG-3' and antisense strand, 5'-ACGUGACACGUUCGGAGAATT-3'). The mock group was defined as the ones supplemented with the transfection reagent only.

Cell proliferation, migration and invasion assays. Cell proliferation was measured by MTT assays as previously described (22). For each assay, $20 \mu 1$ MTT (methyl thiazolyl tetrazolium) was added to each well and incubated for $4 \mathrm{~h}$. For cell migration assay, a wound was created by a p200 pipette tip on cells grown to confluence using 6-well plates; the cell-free space was measured on images captured at both 0 and $48 \mathrm{~h}$. The invasion assays were performed as previously described (22). All experiments were performed in triplicates.

Statistical analysis. The SPSS statistical software package, standard version 17.0 (SPSS, Chicago, IL, USA) was used for statistical analysis. The association between expression of EGFR family members and the clinicopathological variables was analyzed by using Chi-square test. Cumulative overall survival rates were calculated by Kaplan-Meier method and statistical significance for survival curves comparison was analyzed by log-rank test. Univariate and multivariate survival analyses were performed using the Cox multiple hazards model to estimate hazard ratio (HR) and 95\% confidence interval (CI) of each outcome. Differences for all the tests were regarded as statistically significant when the P-value from a two-tailed test was $\mathrm{P}<0.05$.

\section{Results}

Expression and genetic aberrations of EGFR family members in CCAs. Representative cases of positive staining by IHC for each member are shown in Fig. 1. EGFR, HER3 and HER4 were overexpressed in $20(30.8 \%), 8(12.3 \%)$ and 41 (63.1\%) of the 65 IHCCs, and in 23 (20.9\%), 13 (11.8\%) and 62 (56.4\%) 
Table II. Association of expression of EGFR family members with clinicopathological parameters in IHCC.

\begin{tabular}{|c|c|c|c|c|c|c|c|c|c|}
\hline \multirow[b]{2}{*}{ Parameters } & \multicolumn{2}{|c|}{ EGFR } & \multirow[b]{2}{*}{ P-value } & \multicolumn{2}{|c|}{ HER3 } & \multicolumn{3}{|c|}{ HER4 } & \multirow[b]{2}{*}{ P-value } \\
\hline & $\begin{array}{c}\text { Not } \\
\text { overexpressed } \\
(\%)\end{array}$ & $\begin{array}{c}\text { Overexpressed } \\
(\%)\end{array}$ & & $\begin{array}{c}\text { Not } \\
\text { overexpressed } \\
(\%)\end{array}$ & $\begin{array}{c}\text { Overexpressed } \\
(\%)\end{array}$ & P-value & $\begin{array}{c}\text { Not } \\
\text { overexpressed } \\
(\%)\end{array}$ & $\begin{array}{c}\text { Overexpressed } \\
(\%)\end{array}$ & \\
\hline \multicolumn{10}{|l|}{ Age (years) } \\
\hline$<60$ & $23(65.7)$ & $12(34.3)$ & & 31 (88.6) & 4 (11.4) & & $14(40.0)$ & $21(60.0)$ & \\
\hline$\geq 60$ & $22(73.3)$ & 8 (26.7) & 0.507 & $26(86.7)$ & $4(13.3)$ & 1.000 & $10(33.3)$ & $20(66.7)$ & 0.579 \\
\hline \multicolumn{10}{|l|}{ Gender } \\
\hline Male & $18(62.1)$ & $11(37.9)$ & & $23(79.3)$ & $6(20.7)$ & & $11(37.9)$ & $18(62.1)$ & \\
\hline Female & $27(75.0)$ & $9(25.0)$ & 0.262 & $34(94.4)$ & $2(5.6)$ & 0.143 & $13(36.1)$ & $23(63.9)$ & 0.880 \\
\hline \multicolumn{10}{|l|}{ Tumor size } \\
\hline$<5 \mathrm{~cm}$ & $14(63.6)$ & $8(36.4)$ & & $19(86.4)$ & $3(13.6)$ & & $7(31.8)$ & $15(68.2)$ & \\
\hline$\geq 5 \mathrm{~cm}$ & $31(72.1)$ & $12(27.9)$ & 0.485 & $38(88.4)$ & $5(11.6)$ & 1.000 & $17(39.5)$ & $26(60.5)$ & 0.542 \\
\hline \multicolumn{10}{|c|}{$\begin{array}{l}\text { Histological } \\
\text { differentiation }\end{array}$} \\
\hline Well & $15(88.2)$ & $2(11.8)$ & & $17(100)$ & $0(0.0)$ & & $7(41.2)$ & $10(58.8)$ & \\
\hline Moderate & $22(71.0)$ & $9(29.0)$ & & $27(87.1)$ & $4(12.9)$ & & $12(38.7)$ & $19(61.3)$ & \\
\hline Poor & $8(47.1)$ & $9(52.9)$ & 0.033 & $13(76.5)$ & $4(23.5)$ & 0.047 & $5(29.4)$ & $12(70.6)$ & 0.746 \\
\hline \multicolumn{10}{|l|}{$\begin{array}{l}\text { Perineural } \\
\text { invasion }\end{array}$} \\
\hline Negative & $38(66.7)$ & $19(33.3)$ & & $50(87.7)$ & $7(12.3)$ & & $20(35.1)$ & 37 (64.9) & \\
\hline Positive & $7(87.5)$ & $1(12.5)$ & 0.432 & $7(87.5)$ & $1(12.5)$ & 1.000 & $4(50.0)$ & $4(50.0)$ & 0.669 \\
\hline \multicolumn{10}{|l|}{$\begin{array}{l}\text { Vascular } \\
\text { invasion }\end{array}$} \\
\hline Negative & $36(70.6)$ & $15(29.4)$ & & $44(86.3)$ & 7 (13.7) & & $20(39.2)$ & $31(60.8)$ & \\
\hline Positive & $9(64.3)$ & $5(35.7)$ & 0.900 & 13 (92.9) & $1(7.1)$ & 0.838 & $4(28.6)$ & $10(71.4)$ & 0.465 \\
\hline \multicolumn{10}{|l|}{ T stage } \\
\hline $\mathrm{I}+\mathrm{II}$ & $35(68.6)$ & $16(31.4)$ & & $44(86.3)$ & 7 (13.7) & & $16(31.4)$ & 35 (68.6) & \\
\hline III + IV & $10(71.4)$ & $4(28.6)$ & 1.000 & $13(92.9)$ & $1(7.1)$ & 0.838 & $8(57.1)$ & $6(42.9)$ & 0.077 \\
\hline \multicolumn{10}{|l|}{$\begin{array}{l}\text { Lymph node } \\
\text { metastasis }\end{array}$} \\
\hline Negative & $35(70.0)$ & $15(30.0)$ & & $43(86.0)$ & $7(14.0)$ & & $19(38.0)$ & $31(62.0)$ & \\
\hline Positive & $10(66.7)$ & $5(33.3)$ & 1.000 & $14(93.3)$ & $1(6.7)$ & 0.756 & $5(33.3)$ & $10(66.7)$ & 0.743 \\
\hline \multicolumn{10}{|l|}{ UICC stage } \\
\hline $\mathrm{I}+\mathrm{II}$ & $27(67.5)$ & $13(32.5)$ & & $33(82.5)$ & $7(17.5)$ & & $11(27.5)$ & $29(72.5)$ & \\
\hline III + IV & $18(72.0)$ & $7(28.0)$ & 0.702 & $24(96.0)$ & $1(4.0)$ & 0.221 & $13(52.0)$ & $12(48.0)$ & 0.046 \\
\hline
\end{tabular}

of the 110 EHCCs, respectively. Overexpression of HER2 was exclusively identified in EHCCs, among which the rate was $4.5 \%$ (5/110). FISH analysis for EGFR and HER2 was available for 169 and 171 cases, respectively. In all, amplification of EGFR was identified in $1(1.6 \%)$ of the 63 IHCC cases, comparable with that of $2.8 \%(3 / 106)$ in patients with EHCC. By contrast, HER2 amplification was observed in 8 of the $108(7.4 \%)$ EHCC, but was absent in IHCC cases. Of note, a significant association was identified between EGFR amplification and EGFR overexpression $(\mathrm{P}=0.002)$. Similarly, HER2 amplification was strongly associated with HER2 overexpresssion $(\mathrm{P}<0.001)$.

Overall, overexpression of any EGFR family member was found in $47(72.3 \%)$ of 65 patients in IHCC, and $76(69.1 \%)$ of
110 cases in EHCC, respectively. The combination of EGFR and HER4 was the most common, found in $23.1 \%$ of IHCC tumors $(n=15)$ and $12.7 \%$ of EHCC tumors $(n=14)$. In contrast, none of the CCA tumors co-expressed EGFR and HER2.

Associations between EGFR family members with clinicopathological variables. In IHCC, EGFR overexpression was significantly associated with poor histological differentiation $(\mathrm{P}=0.033)$, but not with age $(\mathrm{P}=0.507)$, tumor size $(\mathrm{P}=0.485)$, lymph node metastasis $(\mathrm{P}=1.000)$, vascular invasion $(\mathrm{P}=0.900)$, perineural invasion $(\mathrm{P}=0.432)$ or $\mathrm{UICC}$ stage $(\mathrm{P}=0.702)$ (Table II). In all, 9 EGFR-positive cases were observed in 17 $(52.9 \%)$ poor differentiation samples, whereas only 11 out of 48 $(22.9 \%)$ cases with well and/or moderate differentiation demon- 
A

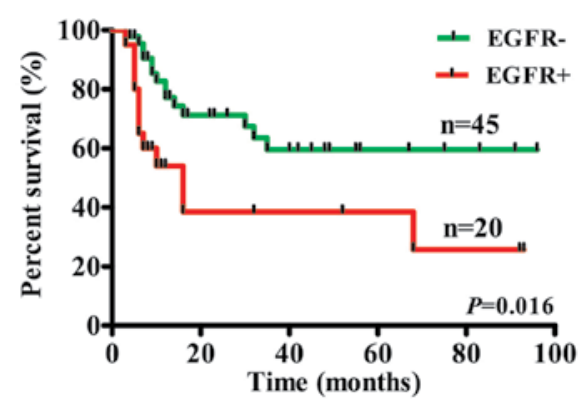

C

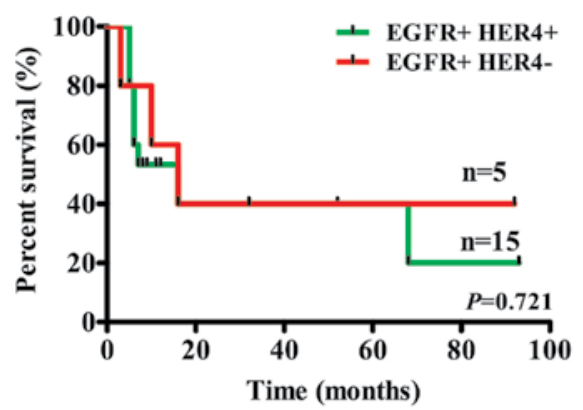

B

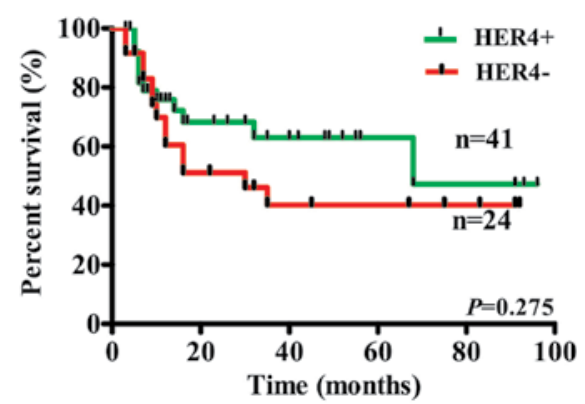

D

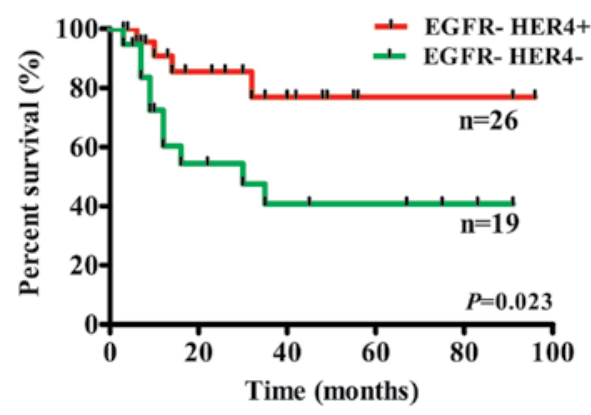

Figure 2. Survival curves stratified by EGFR and HER4 in IHCC (Kaplan-Meier method). Univariate analysis of (A) EGFR and (B) HER4 in IHCC is shown. (C) HER4 is not a prognostic factor in EGFR-positive cases. (D) The outcome of HER4-positive cases was significantly better than that of HER4-negative cases in EGFR-negative IHCCs.

strated EGFR positivity. Poorly differentiated tumors were significantly associated with HER3 overexpression $(\mathrm{P}=0.047)$. By contrast, HER4 expression was associated with UICC I/II stage ( $\mathrm{P}=0.046)$, but not with well differentiation $(\mathrm{P}=0.746)$. No significant association of EGFR amplification was identified with tumor size, histological type, clinical stage, presence of vascular or perineural invasion or lymph node metastases.

In EHCC, EGFR overexpression was significantly associated with well histological differentiation $(\mathrm{P}<0.001)$ and lymph node metastasis $(\mathrm{P}=0.006)$. Overexpression of HER2 was significantly associated with TI/TII stage $(\mathrm{P}=0.050)$, but not with histological differentiation or lymph node metastasis (Table III). No significant correlation was identified between HER3 or HER4 overexpression with other clinicopathological factors.

Univariate and multivariate analyses in CCA. In IHCC, univariate analysis revealed that EGFR overexpression was a prognostic factor $(\mathrm{P}=0.016)$. Additionally, tumor size $(\mathrm{P}=0.022)$ and lymph node metastasis $(\mathrm{P}<0.001)$ were also significantly related to overall survival. Notably, in a multivariate analysis, EGFR overexpression remained an independent prognostic factor [HR (95\% CI): 3.689 (1.253-10.587), $\mathrm{P}=0.018$ ] (Table IV).

In EHCC, 4 factors including EGFR overexpression were identified as prognostic factors by univariate analysis. In multivariate analysis, as shown in Table V, only lymph node status was an independent prognostic factor [HR $(95 \% \mathrm{CI})$ : 2.429 (1.120-5.266), $\mathrm{P}=0.025]$. In contrast, EGFR expression lost its predictive value.

Overall, no statistical significance was identified between HER4 expression and overall survival in CCA by univariate analysis. However, HER4 expression was identified as a prognostic factor $(\mathrm{P}=0.023)$ in EGFR-negative IHCC cases (Table VI). While in EGFR-positive cases, HER4 expression showed no influence on survival rate $(\mathrm{P}=0.721)$ (Fig. 2). In EHCC, no significant correlation was present between HER4 expression and overall survival both in EGFR+ and EGFRcases (data not shown).

Due to a very limited number of HER2-positive cases, survival analysis was not performed for HER2 expression either in univariate or multivariate analysis.

HER4 inhibits cellular proliferation, migration and invasion in CCA cell lines. Using the MTT assay, we found that siRNA knockdown of HER4 in RBE cells significantly increased cell proliferation at 24 and $48 \mathrm{~h}$ after treatment compared with negative controls ( $\mathrm{n}=3, \mathrm{P}<0.05$; Fig. 3 ). Wound healing assay indicated that siRNA-HER4-transfected RBE cells displayed a significant decrease in cell migration ability compared to control conditions $(\mathrm{P}<0.05$; Fig. 3). To further examine the effect of HER4 on cell invasion, siHER4-transfected RBE and PcDNA3.1-HER4-transfected HuCCT-1 cells were cultured in a Transwell apparatus. The percentage of migrated cells was significantly less in siHER4-treated groups when compared to the negative control groups (for both $\mathrm{P}<0.05$ ). PcDNA3.1HER4-transfected HuCCT-1 cell line showed increased percentage of migrated cells (both $\mathrm{P}<0.05$; Fig. 3).

\section{Discussion}

To the best of our knowledge, this is the largest cohort of CCA patients reported thus far, investigating aberrations of all four EGFR family members. Previously, only one 


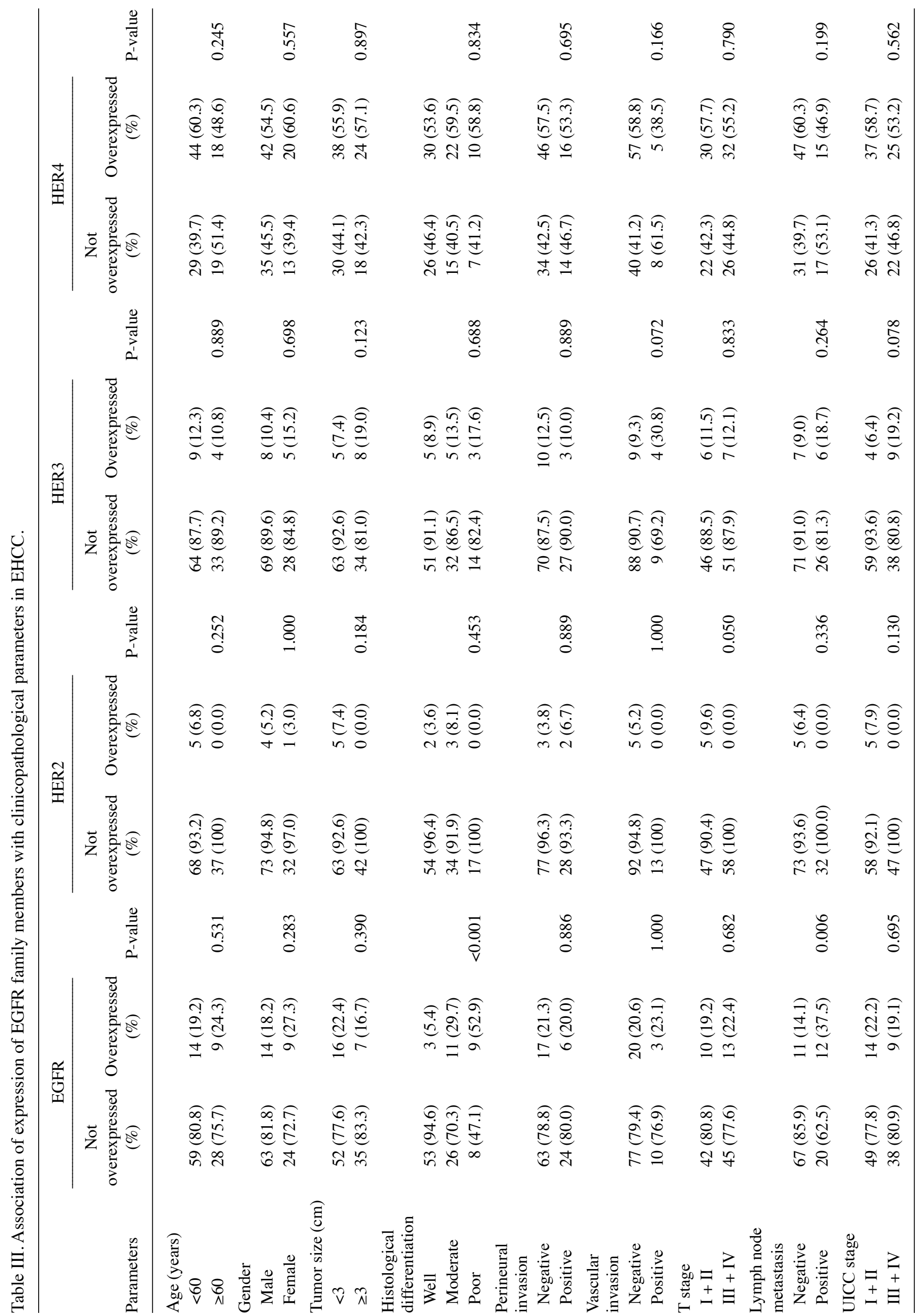


Table IV. Univariate and multivariate analysis of variables associated with survival in IHCC patients.

\begin{tabular}{|c|c|c|c|c|}
\hline \multirow[b]{2}{*}{ Variables } & \multirow[b]{2}{*}{ Coding } & \multirow[b]{2}{*}{ Univariate analysis } & \multicolumn{2}{|c|}{ Multivariate analysis } \\
\hline & & & $\operatorname{HR}(95 \% \mathrm{CI})$ & P-value \\
\hline Tumor size & $<5$ vs. $\geq 5$ & 0.012 & $3.571(1.524-8.370)$ & 0.003 \\
\hline Lymph node metastasis & Neg vs. pos & $<0.001$ & $4.248(1.761-10.249)$ & 0.001 \\
\hline EGFR IHC & Neg vs. pos & 0.016 & $3.689(1.253-10.587)$ & 0.018 \\
\hline
\end{tabular}

Neg, negative; pos, positive.

Table V. Univariate and multivariate analysis of variables associated with survival in EHCC patients.

\begin{tabular}{lccc}
\hline & & & Multivariate analysis \\
\cline { 3 - 4 } Variables & Coding & Univariate analysis & HR (95\% CI) \\
\hline Histological differentiation & Well/moderate vs. poor & $<0.001$ & Non significant \\
pT stage & I + II vs. III + IV & 0.006 & Non significant \\
Lymph node metastasis & Neg vs. pos & $<0.001$ & $2.429(1.120-5.266)$ \\
EGFR IHC & Neg vs. pos & 0.026 & Non significant \\
\hline
\end{tabular}

Neg, negative; pos, positive.

Table VI. Univariate analysis of HER4 expression in patients with IHCC stratified by EGFR.

\begin{tabular}{crcc}
\hline & \multicolumn{2}{c}{ IHCC } & \\
\cline { 2 - 3 } & $\mathrm{N}$ & Survival \% & P-value \\
\hline EGFR- & & & \\
HER4- & 19 & 47.4 & \\
HER4+ & 26 & 84.6 & 0.023 \\
EGFR+ & & & \\
HER4- & 5 & 40.0 & 0.721 \\
HER+ & 15 & 40.0 & \\
\hline
\end{tabular}

study reported expression and clinical significance of all EGFR family members in a small cohort $(n=56)$ of IHCC (24). In the present study, we firstly confirmed a strong link of EGFR to the biological aggressiveness in Chinese CCA patients. The prevalence of EGFR overexpression in CCA has been presented in various reports, ranging from 8.1 to $81 \%(15,17,25,26)$. This broad range might be explained by the lack of a standardized methodology, different standards of interpretation or differences in tumor location. Similar to Yoshikawa et al (15), we detected the frequency of EGFR aberration in our cohort was $30.8 \%$ in IHCC and $20.9 \%$ in EHCC cases. The EGFR overexpression is linked to poor histological differentiation and lymph node metastasis. More importantly, EGFR expression is an independent prognostic indicator in Chinese patients with IHCC. In a systematic review of prognostic biomarkers in CCA, Ruys et al (27) showed that EGFR, along with other biomarkers fascin, MUC1, MUC4 and p27 is associated with survival in patients with resected CCA. To date, EGFR expression in CCA makes it a promising target for EGFR-directed therapy. Preliminary studies suggest that combination chemotherapy using antiEGFR antibody, along with conventional therapeutic agents, increase the efficacy of treatment (28). In a recent clinical phase II trial, Chiorean et al (29) suggested that anti-EGFR therapy remained an important option in advanced biliary cancers but only with a molecular 'targeted' approach.

In the present study, another key finding was that HER4 expression is a prognostic factor in EGFR-negative IHCC cases. To date, the role of HER4 expression in cancer remains controversial. Some studies demonstrated that HER4 acts as a tumor suppressor in aggressive cancers such as the breast, prostate, pancreas and larynx (8,30-33). HER4 expression is antiproliferative and clinically associated with increased survival, reduced recurrence, as well as antagonizing the effect of HER2. By contrast, some reports suggested HER4 overexpression in medulloblastomas and ependymomas possesses oncogenic activities $(34,35)$. In the present study, we provided several lines of evidence to show the antitumor role of HER4 expression in CCA. Firstly, HER4 expression seems to be related to earlier clinical stage and lower tendency of lymph node metastasis, although these did not reach significant difference. Secondly, in vitro data demonstrated that HER4 knockdown in RBE cells promotes cellular proliferation, motility and invasion. Thirdly, a prognostic role of HER4 expression was identified in a subset of IHCC cases. These findings reinforce the importance of molecular subclassification (whether through HER4 status or other relevant biomarkers) of EGFR-negative CCA patients in clinical trials. 


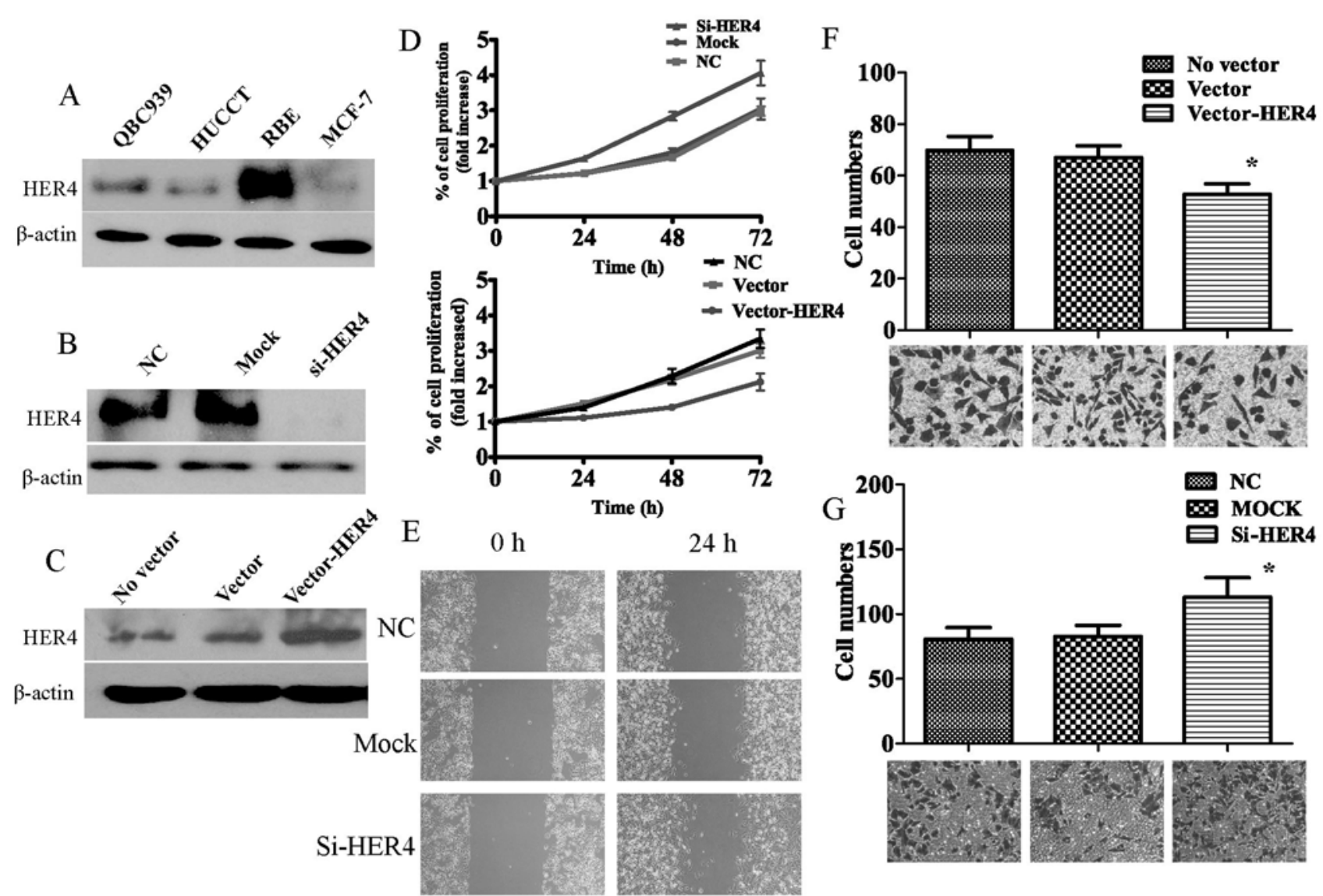

Figure 3. HER4 expression inhibits cellular proliferation, migration and invasion of CCA cells. (A) The protein expression level of HER4 in QBC939, HuCCT-1, RBE and breast cancer cell line MCF-7. (B) HER4 protein expression level after siRNA knockdown of HER4 in RBE cells. (C) HER4 protein expression in pcDNA3.1-HER4 transfected HuCCT-1 cells. (D) Cell proliferation ability assessed by MTT assay in RBE (above) and HuCCT-1 (below), respectively. (E) Effects of siRNA HER4 on RBE cell migration by wound healing assay. Original magnification, x100. (F and G) Cellular invasive capacity of CCA cells assessed by invasion chamber assays; upper, siRNA knockdown of HER4 in RBE cells; lower, pcDNA3.1-HER4 in HuCCT-1 cells. The data shown are the means $\pm \mathrm{SD}$ of triplicate experiments; $\mathrm{P}<0.05$.

The reason why HER4 expression was not a prognostic factor in EHCC might be partially explained by variables associated with their anatomic behavior and methods of surgery. Our data suggested HER4 might play a tumor suppressor role in a selected subset of Chinese CCA patients.

One aim of the present study was to examine the entire spectrum of CCA to define anatomic site-related similarities and differences. Of note, the frequencies of overexpression of EGFR, HER3 and HER4 in EHCC are similar to those of IHCC cases. However, we found that both HER2 overexpression and HER 2 amplification were exclusively identified in EHCC cases. Overall, HER2 overexpression and amplification has been found in a range between 5 and 76\% in CCA $(16,24,25,36)$. Some authors suggested that HER2 overexpression is due to gene deregulation rather than gene amplification as in some studies there is no strict correlation between protein expression and gene amplification (37). However, consistent with Harder et al (11), our data suggested that in CCA cases with high HER2 expression there is also a good correlation between overexpression and amplification. Considering the lack of correlation between HER2 overexpression with other clinical variables, out data suggested that HER2 overexpression might play a role in a subset of EHCC cases, but has limited significance in the development and progression of CCA.
HER3 overexpression was present in $12.3 \%$ (8/65) of IHCC and $11.8 \%(13 / 110)$ of EHCC. The prevalence in this study is significantly lower than almost all of those in previous studies $(19,24)$. HER3 overexpression has been reported to be associated with a poorer outcome in melanomas (38) and lung and gastric cancers (38-40). In CCA, Lee et al (19) suggested that HER3 overexpression is correlated with decreased patient survival and represents a prognostic indicator of patients with EHCC. Notably, they observed the co-overexpression of HER 2 and HER3 in subsets of EHCC patients. However, HER3 expression did not show significant prognostic value in the present study. Thus, the exact biological role of HER3 in CCA merits further investigation.

In summary, our results revealed expression of the EGFR family members in CCA development and progression. CCAs differentially express HER2 protein based on tumor location. For the first time, our study suggested that HER4 is a prognostic factor in subset of EGFR-negative CCA patients with IHCC. Determination of HER4 expression status allows stratification of CCA patients into different survival categories.

\section{Acknowledgements}

The present study was supported by the National Natural Science Foundation of China (grant nos. 81072110 and 
81171951), the Independent Innovation Foundation of Shandong University (grant no. 2010TB012), the Scientific Research Foundation for Returned Scholars, Ministry of Education of China.

\section{References}

1. Malhi $\mathrm{H}$ and Gores GJ: Cholangiocarcinoma: modern advances in understanding a deadly old disease. J Hepatol 45: 856-867, 2006.

2. Khan SA, Thomas HC, Davidson BR and Taylor-Robinson SD: Cholangiocarcinoma. Lancet 366: 1303-1314, 2005.

3. Anderson C and Kim R: Adjuvant therapy for resected extrahepatic cholangiocarcinoma: a review of the literature and future directions. Cancer Treat Rev 35: 322-327, 2009.

4. Zhang H, Berezov A, Wang Q, et al: ErbB receptors: from oncogenes to targeted cancer therapies. J Clin Invest 117: 2051-2058, 2007.

5. Zaczek A, Brandt B and Bielawski KP: The diverse signaling network of EGFR, HER2, HER3 and HER4 tyrosine kinase receptors and the consequences for therapeutic approaches. Histol Histopathol 20: 1005-1015, 2005.

6. Verma S, Miles D, Gianni L, et al: Trastuzumab emtansine for HER2-positive advanced breast cancer. N Engl J Med 367: 1783-1791, 2012.

7. Franklin WA, Veve R, Hirsch FR, Helfrich BA and Bunn PA Jr: Epidermal growth factor receptor family in lung cancer and premalignancy. Semin Oncol 29: 3-14, 2002.

8. Suo Z, Risberg B, Kalsson MG, et al: EGFR family expression in breast carcinomas. c-erbB-2 and c-erbB-4 receptors have different effects on survival. J Pathol 196: 17-25, 2002.

9. Wei Q, Shui Y, Zheng S, et al: EGFR, HER2 and HER3 expression in primary colorectal carcinomas and corresponding metastases: Implications for targeted radionuclide therapy. Oncol Rep 25: 3-11, 2011.

10. Awaya H, Takeshima Y, Furonaka O, Kohno N and Inai K: Gene amplification and protein expression of EGFR and HER2 by chromogenic in situ hybridisation and immunohistochemistry in atypical adenomatous hyperplasia and adenocarcinoma of the lung. J Clin Pathol 58: 1076-1080, 2005.

11. Harder J, Waiz O, Otto F, et al: EGFR and HER2 expression in advanced biliary tract cancer. World J Gastroenterol 15: 4511-4517, 2009.

12. Jaiswal BS, Kljavin NM, Stawiski EW, et al: Oncogenic ERBB3 mutations in human cancers. Cancer Cell 23: 603-617, 2013.

13. Fujiwara S, Ibusuki M, Yamamoto S, Yamamoto Y and Iwase H: Association of ErbB1-4 expression in invasive breast cancer with clinicopathological characteristics and prognosis. Breast Cancer: Oct 26, 2012 (Epub ahead of print).

14. Memon AA, Sorensen BS, Melgard P, Fokdal L, Thykjaer T and Nexo E: Expression of HER3, HER4 and their ligand heregulin-4 is associated with better survival in bladder cancer patients. $\mathrm{Br} \mathrm{J}$ Cancer 91: 2034-2041, 2004.

15. Yoshikawa D, Ojima H, Iwasaki M, et al: Clinicopathological and prognostic significance of EGFR, VEGF, and HER2 expression in cholangiocarcinoma. Br J Cancer 98: 418-425, 2008.

16. Kim HJ, Yoo TW, Park DI, et al: Gene amplification and protein overexpression of HER-2/neu in human extrahepatic cholangiocarcinoma as detected by chromogenic in situ hybridization and immunohistochemistry: its prognostic implication in nodepositive patients. Ann Oncol 18: 892-897, 2007.

17. Shafizadeh N, Grenert JP, Sahai V and Kakar S: Epidermal growth factor receptor and HER-2/neu status by immunohistochemistry and fluorescence in situ hybridization in adenocarcinomas of the biliary tree and gallbladder. Hum Pathol 41: 485-492, 2010.

18. Lubner SJ, Mahoney MR, Kolesar JL, et al: Report of a multicenter phase II trial testing a combination of biweekly bevacizumab and daily erlotinib in patients with unresectable biliary cancer: a phase II Consortium study. J Clin Oncol 28: 3491-3497, 2010.

19. Lee HJ, Chung JY, Hewitt SM, Yu E and Hong SM: HER3 overexpression is a prognostic indicator of extrahepatic cholangiocarcinoma. Virchows Arch 461: 521-530, 2012.

20. Jarnagin WR, Klimstra DS, Hezel M, et al: Differential cell cycle-regulatory protein expression in biliary tract adenocarcinoma: correlation with anatomic site, pathologic variables, and clinical outcome. J Clin Oncol 24: 1152-1160, 2006.
21. Edge SB and Compton CC: The American Joint Committee on Cancer: the 7th edition of the AJCC cancer staging manual and the future of TNM. Ann Surg Oncol 17: 1471-1474, 2010.

22. Wang L, Zhang J, Yang X, et al: SOX4 is associated with poor prognosis in prostate cancer and promotes epithelial-mesenchymal transition in vitro. Prostate Cancer Prostatic Dis 16: 301-307, 2013.

23. Rajkumar T, Stamp GW, Pandha HS, Waxman J and Gullick WJ: Expression of the type 1 tyrosine kinase growth factor receptors EGF receptor, c-erbB2 and c-erbB3 in bladder cancer. J Pathol 179: 381-385, 1996.

24. Ito Y, Takeda T, Sasaki Y, et al: Expression and clinical significance of the erbB family in intrahepatic cholangiocellular carcinoma. Pathol Res Pract 197: 95-100, 2001.

25. Nakazawa K, Dobashi Y, Suzuki S, Fujii H, Takeda Y and Ooi A: Amplification and overexpression of c-erbB-2, epidermal growth factor receptor, and c-met in biliary tract cancers. J Pathol 206: 356-365, 2005.

26. Endreffy E, Burg K, Gyurkovits K, Kalman M, Laszlo A and Rasko I: Allele frequencies of cystic fibrosis-linked markers and F508 deletion in affected Hungarian families. Acta Paediatr Hung 32: 101-113, 1992.

27. Ruys AT, Groot Koerkamp B, Wiggers JK, Klumpen HJ, Ten Kate FJ and van Gulik TM: Prognostic biomarkers in patients with resected cholangiocarcinoma: a systematic review and meta-analysis. Ann Surg Oncol 21: 487-500, 2013.

28. Lee J, Park SH, Chang HM, et al: Gemcitabine and oxaliplatin with or without erlotinib in advanced biliary-tract cancer: a multicentre, open-label, randomised, phase 3 study. Lancet Oncol 13: 181-188, 2012.

29. Chiorean EG, Ramasubbaiah R, Yu M, et al: Phase II trial of erlotinib and docetaxel in advanced and refractory hepatocellular and biliary cancers: Hoosier Oncology Group GI06-101. Oncologist 17: 13, 2012.

30. Barnes NL, Khavari S, Boland GP, Cramer A, Knox WF and Bundred NJ: Absence of HER4 expression predicts recurrence of ductal carcinoma in situ of the breast. Clin Cancer Res 11: 2163-2168, 2005

31. Edwards J, Traynor P, Munro AF, Pirret CF, Dunne B and Bartlett JM: The role of HER1-HER4 and EGFRvIII in hormonerefractory prostate cancer. Clin Cancer Res 12: 123-130, 2006.

32. Thybusch-Bernhardt A, Beckmann S and Juhl H: Comparative analysis of the EGF-receptor family in pancreatic cancer: expression of HER-4 correlates with a favourable tumor stage. Int J Surg Investig 2: 393-400, 2001.

33. Bussu F, Ranelletti FO, Gessi M, et al: Immunohistochemical expression patterns of the HER4 receptors in normal mucosa and in laryngeal squamous cell carcinomas: antioncogenic significance of the HER4 protein in laryngeal squamous cell carcinoma. Laryngoscope 122: 1724-1733, 2012.

34. Gilbertson RJ, Perry RH, Kelly PJ, Pearson AD and Lunec J: Prognostic significance of HER2 and HER4 coexpression in childhood medulloblastoma. Cancer Res 57: 3272-3280, 1997.

35. Rickert CH: Prognosis-related molecular markers in pediatric central nervous system tumors. J Neuropathol Exp Neurol 63: 1211-1224, 2004.

36. Settakorn J, Kaewpila N, Burns GF and Leong AS: FAT, E-cadherin, $\beta$ catenin, HER 2/neu, Ki67 immuno-expression, and histological grade in intrahepatic cholangiocarcinoma. J Clin Pathol 58: 1249-1254, 2005.

37. Buchler P, Reber HA, Buchler MC, et al: Therapy for pancreatic cancer with a recombinant humanized anti-HER 2 antibody (herceptin). J Gastrointest Surg 5: 139-146, 2001.

38. Reschke M, Mihic-Probst D, van der Horst EH, et al: HER3 is a determinant for poor prognosis in melanoma. Clin Cancer Res 14: 5188-5197, 2008.

39. Yi ES, Harclerode D, Gondo M, et al: High c-erbB-3 protein expression is associated with shorter survival in advanced non-small cell lung carcinomas. Mod Pathol 10: 142-148, 1997.

40. Begnami MD, Fukuda E, Fregnani JH, et al: Prognostic implications of altered human epidermal growth factor receptors (HERs) in gastric carcinomas: HER2 and HER 3 are predictors of poor outcome. J Clin Oncol 29: 3030-3036, 2011. 